\title{
Microsurgical Gross Total Resection of a WHO Grade II Cerebellopontine Angle Ependymoma in an Adult
}

\author{
Sima Sayyahmelli ${ }^{1}$ Melih Ucer $^{1}$ Mustafa K. Baskaya ${ }^{1}$ \\ ${ }^{1}$ Department of Neurological Surgery, University of Wisconsin \\ Medical School, Madison, Wisconsin, United States \\ Address for correspondence Mustafa K. Baskaya, MD, Department of \\ Neurological Surgery, University of Wisconsin Medical School, K4/834 \\ CSC, 600 Highland Avenue, Madison, WI 53792-0001, United States \\ J Neurol Surg B 2018;79(suppl S5):S426-S427. \\ (e-mail: baskaya@neurosurgery.wisc.edu).
}

\begin{abstract}
Keywords

- cerebellopontine angle

- ependymoma

- surgical resection

- adult

Infratentorial ependymomas that arise in the fourth ventricle and extend into the cerebellopontine angle (CPA) through the foramina of Luschka are well described. However, a primary CPA location of an ependymoma is distinctly uncommon. In this video, we present a 46-year-old man with episodes of dizziness, left-sided tinnitus, imbalance, double vision, and nausea. An magnetic resonance imaging (MRI) scan of the head showed a large mass lesion centered in the CPA with heterogenous enhancement. Differential diagnosis included ependymoma, meningioma, schwannoma of the vestibular nerve, or lower cranial nerves, and choroid plexus papilloma. He underwent microsurgical gross total resection of the tumor via a retrosigmoid approach. Direct stimulation of the cranial nerves was performed throughout the case and there was no attachment of the tumor to any cranial nerve to suggest that this might be a schwannoma. The tumor encased important vasculature, including the posterior-inferior cerebellar artery. The histopathology was a grade II ependymoma. The patient tolerated the surgery well and his postoperative course was uneventful. He remained neurologically intact. He received radiation therapy and there was no recurrent or residual disease on follow-up studies. This video demonstrates important steps of the surgical approach and microsurgical resection techniques for this type of challenging tumor.

The link to the video can be found at: https://youtu.be/KK-y6EYh888.
\end{abstract}

Conflict of Interest

None.

Disclosure of Funding

None.

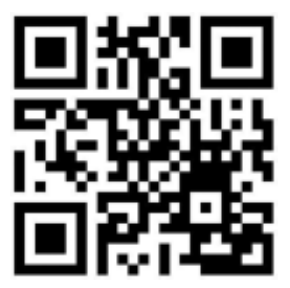

received

May 30, 2018

accepted

August 12, 2018

published online

September 25, 2018

www.thieme.com/skullbasevideos

www.thieme.com/jnlsbvideos

DOI https://doi.org/

10.1055/s-0038-1669969.

ISSN 2193-6331. (c) 2018 Georg Thieme Verlag KG Stuttgart · New York
License terms

(c) (i) $\ominus$ (5) 


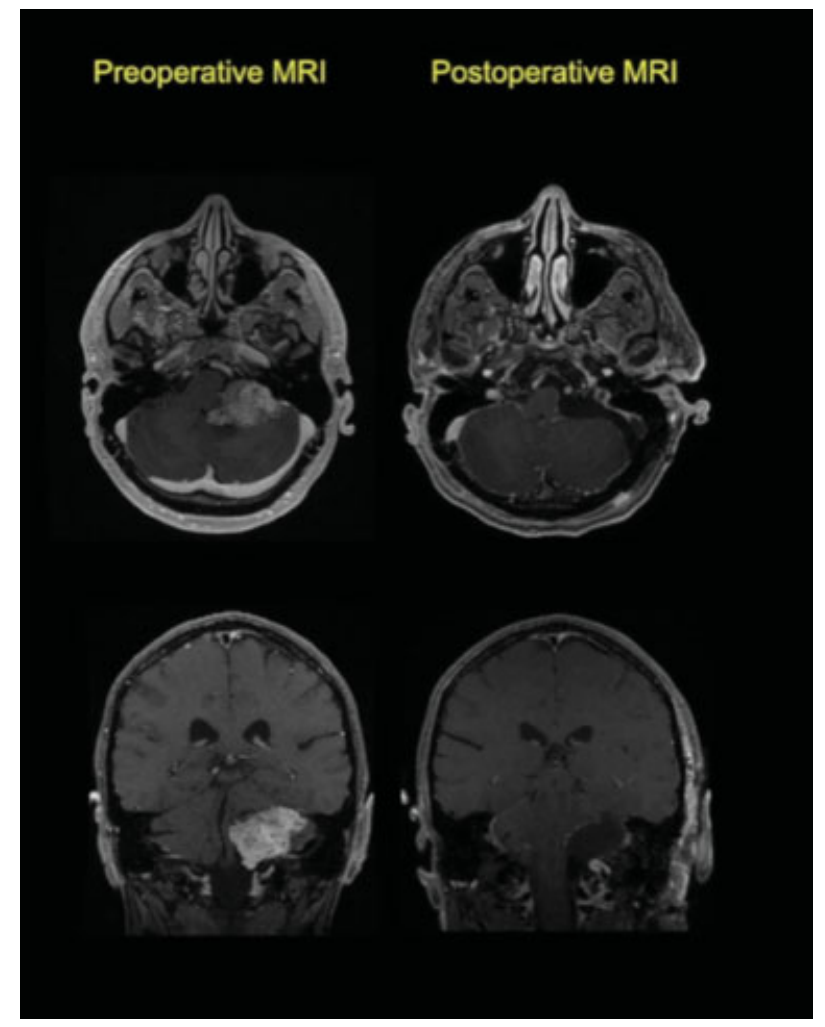

Fig. 1 Pre and postoperative magnetic resonance imaging.

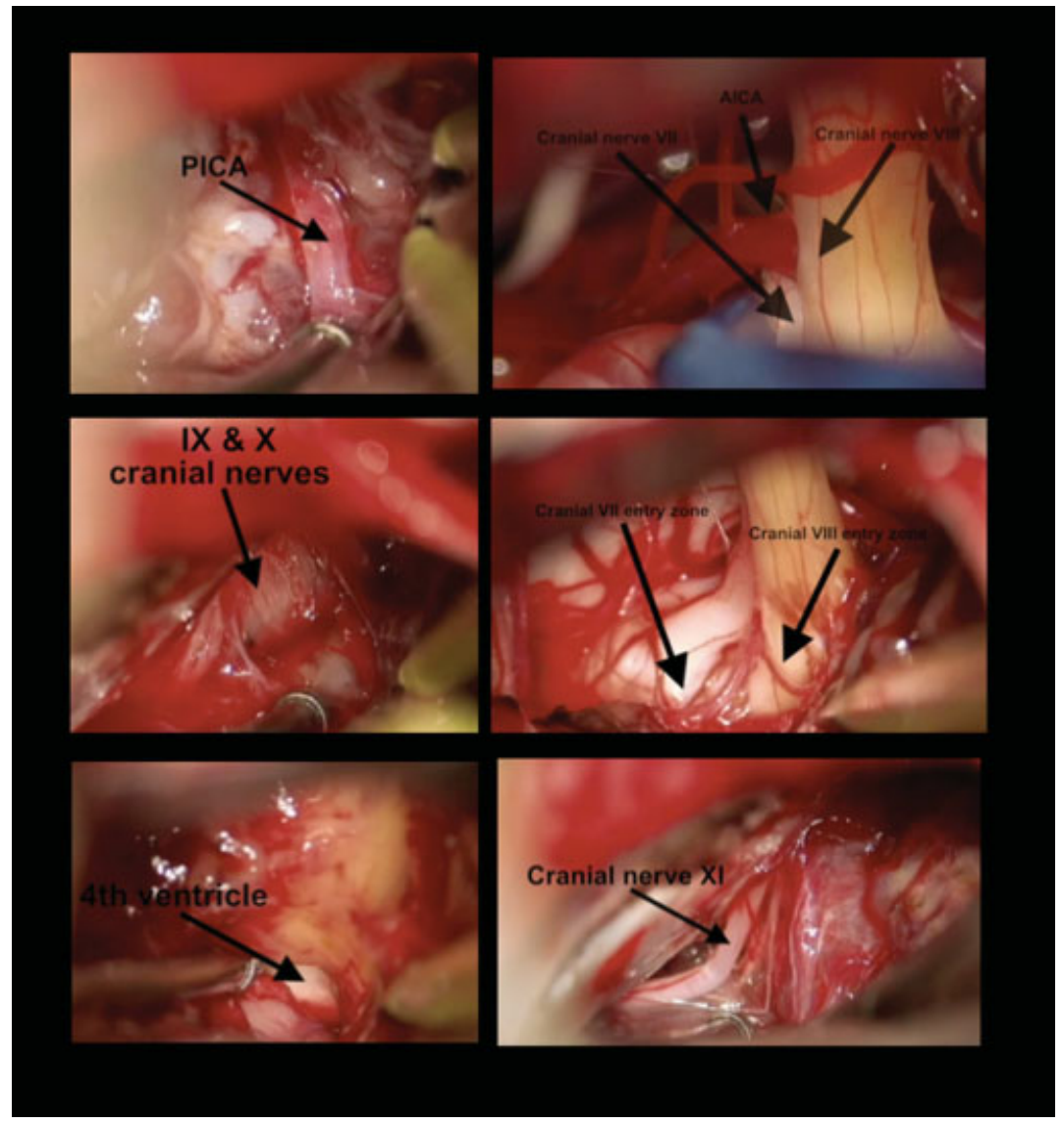

Fig. 2 Intraoperative images. 